\title{
ALCOHOL USE AMONG WOMEN IN A TOWN OF EASTERN NEPAL
}

\author{
Niraula S R*, Shyangwa P M*, Jha N, Paudel R K*, Pokharel P K
}

\section{ABSTRACT}

A community-based cross-sectional survey with cluster sampling method (probability proportionate to size) was carried out to estimate the prevalence of alcohol consumption among Nepalese women in Dharan town to assess the pattern of use and to identify the factors associated with this habit. A representative sample of 2340 women, aged 15 years and above was interviewed in 2002. The estimated prevalence of alcohol consumption was nearly $17 \%$. Alcohol use is prevalent among females of hill ethnic groups. Nearly half of the divorced (formal or informal) women consumed alcohol. The women, aged 50 years and above, were at risk to become addicted to its use. Most popular drink in this area is a homemade product (Local Raksi). The alcohol users are more likely to smoke as well. More than $9 \%$ of pregnant women are found to consume alcohol during their pregnancy. Effective awareness programs are required to discourage the excessive use of alcohol among women and encourage those seeking regular health care services.

\section{Key Words: Prevalence, pattern, factors, women, alcohol, Dharan, Nepal.}

\section{INTRODUCTION}

The use of alcohol is described in ancient scriptures like 'VEDAS', 'KIRAT MUNDHAM' and 'BIBLE'. Alcoholic beverages have a long tradition in Nepal. In worshiping Gods and Goddesses as well as other ritual practices, alcohol is still offered by quacks and faith healers in some communities. The use of alcohol has become common in feasts, festivals, ceremonies and parties. The use of alcohol becomes a problem if it exceeds the limits of quantity and frequency. The World Health Assembly in 1983 has declared alcohol-related problems to be a major public health concern all over the world. The term 'alcohol problems' (problems caused by alcohol that may require treatment) refers to a broad array of acute and chronic medical, behavioral and social problems. ${ }^{1}$ Although alcohol consumption has shown a decline in the developed countries in recent times, it has been rising rapidly in developing countries including Nepal. (Global Status Report on Alcohol No. 1211, WHO Substance Abuse Department, Unpublished report.)
Nepal is a small country covering an area of 147,181 sq. $\mathrm{km}$. with the population 23 million above ${ }^{2}$ bordered by two big countries-India and China. Dharan is a town situated in eastern Nepal, where majority of people belong to hilly ethnic groups (Rai, Limbu, Gurung, Tamang, etc). Alcohol consumption has been a part of their way of living, as it is highly demanded in their social, religious and cultural occasions. Alcohol use is also seen among occupational castes like Bishwakarma, Pariyar, Sarki, etc.

Beside that, in some rural areas, alcohol use is encouraged to pregnant women during delivery to get rid of labor-pain. Female alcoholism is a serious public health problem, as it not only has a negative impact on the health of a pregnant woman, but also on her fetus. Furthermore, females are more vulnerable to many serious consequences of alcohol use in comparison to male; for example, the female can develop physical problem dependence earlier than the male. A study conducted in Dharan shows that nearly $26 \%$ of females are

* B.P. Koirala Institute of Health Sciences, Dharan, Nepal.

Address for correspondence : Surya Raj Niraula

B.P. Koirala Institute of Health Sciences, Dharan, Nepal.

Email: sniraula@yahoo.com 
alcohol dependent (CAGE 2). ${ }^{3}$ In addition to this, a hospital based study within 16-month period at B P Koirala Institute of Health Sciences, Dharan, reveals that $70 \%$ of women are admitted to medical ward with alcohol related physical problems. Over $90 \%$ of them belong to hill-country ethnic groups. ${ }^{4}$ Alcohol use among women may reach alcohol abuse and dependence ${ }^{5}$ if it is not controlled in time. In the light of these facts, a necessity was felt to conduct a study on alcohol use among women in Dharan. Therefore, this study, a part of the survey, was carried out in an attempt to estimate the prevalence of alcohol use among Nepalese females, to assess the pattern and preference of alcoholic products, and the factors associated with the habit.

\section{MATERIALS AND METHODOLOGY}

\section{Study population and sampling}

The study is a cross-sectional survey, conducted in Dharan Municipality in 2002. The municipality has 19 wards with a population of 95 thousands (approx.). Among them, the females aged 15 years and above comprise around $30 \%{ }^{6}$. The sample size was preliminarily estimated on the basis of the prevalence of alcohol use (8.3\%) among females in urban areas of the Sunsari district, which includes Dharan, too. ${ }^{7}$ As the population is heterogeneously distributed in the wards, the cluster sampling with Probability Proportionate to Sample Size (PPS) technique is used to represent the target population. Considering the design effect 2 and $10 \%$ of non-response rate, 2340 subjects were required to represent the women in Dharan for alcohol consumption. Thirty clusters of size 78 females each were selected from 19 wards.

\section{Data Collection Procedure}

This study was approved by the Ethical Review Board of Research Committee of B. P. Koirala Institute of Health Sciences, one of the authorized institutions of Nepal Health Research Council, Kathmandu. Before the data collection, written permission was taken from the Municipality to conduct the study. The selection of houses was made randomly using numbers from 11 to 49 ; the first digit indicates direction from

Table I : Prevalence of alcohol consumption among the women by socio-demographic characteristics; Dharan, 2002

\begin{tabular}{|c|c|c|c|}
\hline & Number & Percentage & Prevalence, \% \\
\hline All & 2340 & 100.0 & 16.8 \\
\hline \multicolumn{4}{|l|}{ Age group (years) } \\
\hline $15-24$ & 933 & 39.9 & 2.1 \\
\hline $25-34$ & 582 & 24.9 & 15.1 \\
\hline $35-44$ & 250 & 10.7 & 31.2 \\
\hline $45-54$ & 279 & 11.9 & 36.2 \\
\hline $55-64$ & 190 & 8.1 & 38.9 \\
\hline $65+$ & 106 & 4.5 & 29.2 \\
\hline \multicolumn{4}{|l|}{ Reproductive and old age } \\
\hline $15-49$ & 1902 & 81.3 & 12.2 \\
\hline $50+$ & 438 & 18.7 & 36.5 \\
\hline \multicolumn{4}{|l|}{ Marital Status } \\
\hline Unmarried & 725 & 31.0 & 0.6 \\
\hline Married & 1376 & 58.8 & 21.7 \\
\hline Widow & 196 & 8.4 & 35.2 \\
\hline Separated/ Divorced & 43 & 1.8 & 46.5 \\
\hline \multicolumn{4}{|l|}{ Occupation } \\
\hline Housewife & 1312 & 56.1 & 23.9 \\
\hline Business & 187 & 8.0 & 26.7 \\
\hline White color job holder & 137 & 5.8 & 2.9 \\
\hline Laborer & 78 & 3.3 & 29.5 \\
\hline Student & 605 & 25.9 & 0.0 \\
\hline Unemployed & 21 & 0.9 & 4.8 \\
\hline \multicolumn{4}{|l|}{ Ethnicity* } \\
\hline Hill Native Castes & 1219 & 52.1 & 23.4 \\
\hline Major Hill Castes & 759 & 32.4 & 9.0 \\
\hline Hill Occupational Castes & 156 & 6.7 & 14.7 \\
\hline Terai Castes & 206 & 8.8 & 7.8 \\
\hline \multicolumn{4}{|l|}{ Religion } \\
\hline Hindu & 1659 & 70.9 & 16.0 \\
\hline Kirat & 300 & 12.8 & 26.0 \\
\hline Buddhist & 216 & 9.2 & 22.2 \\
\hline Others & 165 & 7.1 & 0.6 \\
\hline
\end{tabular}

* Ethnicity Hill Native - Rai, Limbu, Magar, Tamang, Gurung, Sherpa; Major Hill - Brahmin, Chhetri, Newar; Hill Occupation - Bishwakarma, Sarki; Terai Caste - Marwadi, Yadav, Jha, Rauniyar, Gupta, Malik etc. ${ }^{6}$ 
a junction of streets, and the second digit indicates the number of house to begin the survey. The interview was taken by three female enumerators, and continued till 78 women for each cluster was completed. The enumerators were trained by the investigators on interview technique and filling up the questionnaire. Verbal consent was obtained from each respondent. All subjects in each cluster agreed to take part in the interview after the study objectives were explained to them. The females who were not at home during the study visits were excluded. The "Alcohol consumer" refers to a female who used alcohol at least once in the previous year.

\section{Instrument}

The data collection instrument was a self-designed questionnaire in Nepali language; it consisted of different questions about age, marital status, occupation, ethnicity, religion, and pregnancy status, type, frequency, duration and quantity of alcohol consumed, tobacco chewing and/or smoking habit, and self reported health problems of the women, etc. The questionnaire was pre-tested on 20 females at nearby Village 'Tarahara'. The reliability was tested using the Guttman split-half reliability coefficient. It was calculated as 0.68 , indicating that overall participants consistently responded to questionnaire items.

\section{Data analysis}

The data were entered into dBASE IV software and checked regularly by an analyst. The analysis was done in SPSS version
10.0. Setting the level of significance at 5\%, 95\% Confidence Interval, Odds Ratio, Chi-square, were calculated to know the significance of the variables. Logistic regression was used to identify the factors associated with alcohol use.

\section{RESULTS}

\section{Sample Characteristics}

The overall sample consisted of 2340 women among whom nearly $40 \%$ were in the age group of 15 to 25 years. Most of the subjects were housewives $(56.1 \%)$ and married women (58.8\%). The Hindu (70.9\%) and hill ethnic group $(52.1 \%)$ subjects dominated the sample.

The prevalence of alcohol consumption was found to be $16.8 \%$ $(96 \% \mathrm{CI}=15.3 \%, 18.3 \%)$; it increased with increasing age groups from $2.1 \%$ in the 15 -to-24 year age group to peak at $38.9 \%$ in the 55-to-64 year age group, after which it decreased at $29.2 \%$ in the $65+$ year age group $\left(\div^{2}=343.5\right.$, d.f. $=5$, $\mathrm{P}<0.0001)$. Of the total, $36.5 \%$ of those in age 50 years and above $(95 \% \mathrm{CI}=32.0 \%, 41.2 \%)$, compared with $12.2 \%(95 \%$ $\mathrm{CI}=10.8 \%, 13.8 \%)$ of the reproductive age group 15-to-49 year were found to be alcohol users $\left(\div^{2}=43.6\right.$, d.f. $\left.=1, \mathrm{P}<0.0001\right)$. Most of separated/divorced women and widows were found to take alcohol in comparison with others $\left(\div^{2}=236.6\right.$, d.f. $=3$, $\mathrm{P}<0.0001)$. The prevalence was highest among laborers $(29.5 \%)$, however no school and college-going student was found to use alcohol. The frequency of alcohol use was found

Table II : Pattern of alcohol consumption among the women; Dharan, 2002

\begin{tabular}{|c|c|c|c|c|}
\hline \multirow[t]{2}{*}{ Alcohol consumption } & \multicolumn{2}{|c|}{ Age group (years), \% } & \multirow[t]{2}{*}{ Total, \% } & \multirow[t]{2}{*}{ Significance } \\
\hline & $15-49$ & $50+$ & & \\
\hline Total & 232 & 160 & 392 & \\
\hline \multicolumn{5}{|l|}{ Type* } \\
\hline Distilled home made products & 56.5 & 50.6 & 54.1 & \multirow{4}{*}{$\begin{array}{r}? 2=21.3, \mathrm{df}=3, \\
\mathrm{P}<0.0001\end{array}$} \\
\hline Non-distilled home made products & 22.0 & 40.6 & 29.6 & \\
\hline Industrial distilled products & 6.9 & 2.5 & 5.1 & \\
\hline Industrial non-distilled products & 14.7 & 6.3 & 11.2 & \\
\hline \multicolumn{5}{|l|}{ Frequency } \\
\hline Daily & 20.7 & 39.4 & 28.3 & \multirow{4}{*}{$\begin{array}{r}? 2=26.2, \mathrm{df}=3 \\
\mathrm{P}<0.001\end{array}$} \\
\hline 2-3 times/week & 6.9 & 13.1 & 9.5 & \\
\hline Once a week & 1.7 & 2.5 & 2.0 & \\
\hline Occasional & 70.7 & 45.0 & 60.2 & \\
\hline \multicolumn{5}{|l|}{ Duration (years) } \\
\hline$<5$ & 39.2 & 1.3 & 23.7 & \multirow{5}{*}{$\begin{array}{r}? 2=113.2, \mathrm{df}=4, \\
\mathrm{P}<0.0001\end{array}$} \\
\hline $6-10$ & 21.6 & 8.8 & 16.3 & \\
\hline $11-15$ & 7.3 & 7.5 & 7.4 & \\
\hline $16-20$ & 3.9 & 10.0 & 6.4 & \\
\hline$>20$ & 28.0 & 72.5 & 46.2 & \\
\hline \multicolumn{5}{|l|}{ Quantity** } \\
\hline Half glass & 56.9 & 45.6 & 52.3 & \multirow{3}{*}{$\begin{array}{r}? 2=5.9, \mathrm{df}=2, \\
\text { Not Significant }\end{array}$} \\
\hline One glass & 39.2 & 46.9 & 42.3 & \\
\hline Two glass and more & 3.9 & 7.5 & 5.4 & \\
\hline $\begin{array}{ll}\text { Type: } & \frac{\text { Homemade distilled product }}{\text { Industial distilled product }-} \\
\text { Ouanty: } & \frac{\text { One glass }-175 \mathrm{ml} \text { (approxi }}{}\end{array}$ & alsi. nu & nrodu & $\begin{array}{l}\text { Tongba, Ch } \\
\text {-distilled pro }\end{array}$ & $\begin{array}{l}n g, \text { Jand, etc; } \\
t-\text { Beer, Wine, etc. }\end{array}$ \\
\hline
\end{tabular}


to be highest $(23.4 \%)$ among the hill native tribes, and lowest $(7.8 \%)$ among the Terai castes $\left(\dot{\div}^{2}=83.8\right.$, d.f. $\left.=3, \mathrm{P}<0.0001\right)$. More women of Kirat ethnic groups consumed alcohol (26.0\%) in comparison to others $\left(\div^{2}=54.6\right.$, d.f. $\left.=3, \mathrm{P}<0.0001\right)$. (Table I)

\section{Pattern of alcohol consumption}

About $54 \%$ of the alcohol-consuming women took homemade distilled product, 'Local Raksi', followed by homemade nondistilled products $(29.6 \%)$ like Jand, Tongba, Chhyang, etc. Among industrial products, non-distilled products, Beer, Wine $(11.2 \%)$ were consumed nearly double of the distilled products like Whisky, Vodka, Rum etc. (5.1\%). Daily users were more common in age group 50 years and above (56.8\%) whereas, occasional users were common in age group (15-49) (60\%). Also, long-term alcohol consumption i.e. "20 year duration" was common among females of the age group 50 years and above $(64.1 \%)$. More than half consumers $(52.3 \%)$ took about half a glass of alcohol (approximately $175 \mathrm{ml}$.). The type, frequency and duration significantly varied according to age groups but no significant different was found in the quantity of consumption. (Table II)

\section{Factors associated with alcohol consumption}

Table III shows that $9.4 \%$ of pregnant women took alcohol and it was significantly lower in comparison with the prevalence among non-pregnant married women $\left(\div^{2}=23.21\right.$, d.f. $\left.=1 \mathrm{P}<0.0001\right)$. The factors associated with alcohol consumption are shown in table IV. The women aged 50 years and above were more likely to take alcohol than the women in the reproductive age $(\mathrm{OR}=2.4, \mathrm{P}<0.0001)$. Unmarried women were less likely to take alcohol than others. The business and laborer class women were more likely to have alcohol habit than the housewives; but even these women were less likely to have the habit than white collar jobholders.

Table III : Alcohol used by married women in pregnancy; Dharan, 2002 ( $\mathrm{n}=1381)$

\begin{tabular}{|c|c|c|c|c|}
\hline \multirow[t]{2}{*}{ Pregnancy } & \multicolumn{2}{|c|}{ Alcohol use } & \multirow[t]{2}{*}{ Total $(n=1381)$} & \multirow[t]{2}{*}{ Significance } \\
\hline & Yes & No & & \\
\hline Yes & 9.4 & 96.6 & 20.5 & \multirow{3}{*}{$? 2=151.1, \mathrm{df}=1, \mathrm{P}<0.0001$} \\
\hline No & 24.2 & 75.8 & 79.5 & \\
\hline Total & 21.6 & 78.4 & 100.0 & \\
\hline
\end{tabular}

Table IV : Factors associated with prevalence of alcohol consumption among the women aged 15 years above; Dharan, 2002 (Logistic regression model)

\begin{tabular}{|c|c|c|c|c|}
\hline \multirow[t]{2}{*}{ Covariates } & \multirow[t]{2}{*}{ Odds Ratio } & \multicolumn{2}{|c|}{ 95.0\% C.I. } & \multirow{2}{*}{$\begin{array}{c}\text { Significance } \\
\text { level }\end{array}$} \\
\hline & & Lower & Upper & \\
\hline Age above 50years & 2.395 & 1.706 & 3.363 & $<0.0001$ \\
\hline \multicolumn{5}{|l|}{ Marital Status } \\
\hline Unmarried (reference category) & 1.0 & & & \\
\hline Married & 9.782 & 3.143 & 30.443 & $<0.0001$ \\
\hline Widow & 17.263 & 5.075 & 58.720 & $<0.0001$ \\
\hline Separated/divorced & 33.187 & 8.448 & 130.369 & $<0.0001$ \\
\hline \multicolumn{5}{|l|}{ Occupation } \\
\hline Housewife (reference category) & 1.0 & & & \\
\hline Business & 1.776 & 1.160 & 2.719 & $<0.009$ \\
\hline White color job holder & 0.220 & 0.077 & 0.630 & $<0.005$ \\
\hline Labors & 3.061 & 1.549 & 6.050 & $<0.001$ \\
\hline Student & 1.467 & 0.157 & 13.729 & NS* \\
\hline Unemployed & 0.001 & 0.000 & 252.995 & NS* \\
\hline \multicolumn{5}{|l|}{ Caste/ethnicity } \\
\hline Hill native caste (reference category) & 1.0 & & & \\
\hline Major hill caste & 0.305 & 0.212 & 0.437 & $<0.0001$ \\
\hline Hill occupational caste & 0.688 & 0.366 & 1.295 & NS* \\
\hline Terai caste & 0.277 & 0.146 & 0.525 & $<0.0001$ \\
\hline \multicolumn{5}{|l|}{ Religion } \\
\hline Hindu (reference category) & 1.0 & & & \\
\hline Kirat & 0.846 & 0.582 & 1.231 & NS* \\
\hline Buddhist & 0.761 & 0.491 & 1.181 & NS* \\
\hline Others & 0.047 & 0.006 & 0.382 & $<0.005$ \\
\hline Smokeless tobacco user & 1.088 & .798 & 1.484 & NS* \\
\hline Smokers & 1.604 & 1.161 & 2.216 & $<0.005$ \\
\hline Self reported unhealthy & 0.840 & 0.643 & 1.098 & NS* \\
\hline At least an alcohol member in family & 11.808 & 7.288 & 19.130 & $<0.0001$ \\
\hline
\end{tabular}


Alcoholic habit was strongly associated with major hill and Terai caste women. The Hindu religious women were more likely to have alcohol-drinking habit than Christian and Muslim women. The significant factors associated with alcohol consumption were smoking ( $\mathrm{OR}=1.6, \mathrm{P}<0.005)$; and at least an alcoholic member in the family $(\mathrm{OR}=11.8, \mathrm{P}<0.0001)$. Self reported health problem was not significantly associated with the habit of alcohol consumption. (Table IV)

\section{DISCUSSION}

This study suggests that the prevalence of alcohol consumption among the women in Dharan was nearly 17\%. This figure is nearly double of the result of a study conducted in 1994, which reported that $8.3 \%$ of females consumed alcohol within past one month in urban areas of the Sunsari district.? Though, a small increment may be due to the exclusion of the females aged less than 15 years in the present study, the trend of consumption is obviously increased. The study ${ }^{7}$ also supports the finding that the prevalence of alcohol use increased with the increasing age groups to peak in the 55-to-64 year age interval after which, it decreased in $65+$ year age group. Similar result was reported in a study done in Taiwan. ${ }^{8}$

This study shows that hill native castes are most likely to consume alcohol than other castes. The hill native castes, also called 'Matawali', have a second high prevalence rate of alcohol dependence (29.7\%) in Dharan. ${ }^{4}$ Generally these castes come from hill areas of northern Nepal where life is quite hard. For easy life and better job opportunities, these people migrated from the hill to the Terai; therefore, there is a good number of these castes in the town. They demand alcohol for social, cultural and religious purposes. Nearly $20 \%$ of the Nepalese society is made up this category. ${ }^{2}$

The finding suggests that married women are less likely to consume alcohol than the separated, divorced women and widows. There are a few unmarried females who also used to take alcohol. The result might not show the real picture in that subject group as the number of divorced and separated women was too small to draw a conclusion and it is therefore, considered a limit. This study is silent on family income of the respondents because most of them did not want to tell it, however, they confirmed that the data will not be disclosed for any other purpose. It may be due to the fear of Maoists. During the survey, the country suffered increasing attacks on properties and incidents of violence related to brutal Maoist insurgency.

The study revealed that the use of homemade rather than industrial products was more common among the female alcohol-consumers. The reason may be that it can be produced in one's own house, is cheaper in cost and raw materials for preparation are easily available. The result supports the finding of a study done in the same district, Sunsari. ${ }^{7}$ Although there is a rapid increase in the advertisement of industrial products through different media, it is contrary to the practices in developing countries like Nepal, however, in developed countries like Denmark, the industrial products like beer and wines are more popular. ${ }^{9}$ Among alcohol consumers, nearly half of them have continuously been taking alcohol for more than 20 years. The quantity and frequency of alcohol should be limited; otherwise, excess of consumption may lead to many health hazards. The adverse effects of heavy drinking seem to be partially mediated through its effect on body weight. ${ }^{10}$ Many studies support that heavy drinking is a risk factor for diabetes. ${ }^{11,12,13}$

Daily users are more coming among the women aged 50 years and above. Problems related to alcohol use and misuse can seriously affect many of the health concerns common among older women, including chronic illness and depression. ${ }^{12} \mathrm{~A}$ prospective study among women of Maryland adds evidence that the assessment of vulnerability to heavy alcohol use in women includes consideration of depression. ${ }^{13}$

The females in this study reported that they didn't have any significant health effects due to alcohol consumption. However, the self-reported health problem might not have any accuracy. Self-reported morbidity has severe limitations and can be extremely misleading. ${ }^{14}$ In Nepal, cases of alcohol abuse, with all its adverse effects do not come to the attention of doctors; they are mostly tolerated or seemingly treated with dubious results by 'local quacks', and faith healers. Despite high prevalence, records show that not more than $2 \%$ of the patients attending psychiatric clinics in Nepal reports any alcohol-related problem. ${ }^{15}$ An additional study is recommended to screen alcohol problems and alcohol dependence among the women using some standard scales. Again the result shows that alcohol drinking is positively associated with smoking which has a high risk factor for different diseases like cancer, asthma, adenoma, etc. It is supported by a prospective study done in Japanese men and women, which reported the association of alcohol use and smoking with the risk of adenoma. ${ }^{16}$

Although the rate of alcohol consumption among pregnant women (9\%) was less in comparison to non-pregnant women (24.2\%), this finding nevertheless presents a significant public health problem. Despite vigorous efforts to increase public awareness about the hazards of taking alcohol during pregnancy, these pregnant would-be women still disbelieve the facts. They drink alcohol during delivery to get rid of the travail. Drinking during pregnancy has been associated with major neuro-developmental and other birth defects and more subtle abnormalities in later childhood. ${ }^{17}$ Other effects of 
alcohol are an increase in low fetal birth weight ${ }^{18}$ and spontaneous abortions. ${ }^{19,20}$ Therefore, alcohol consumption among females should be discouraged through effective media.

\section{CONCLUSION}

The prevalence of alcohol consumption among women in Dharan is nearly $17 \%$. Alcohol consumption among Nepalese women may be doubled again if the group is not made aware in time. It is more common among the women aged 50 years and above. Separated women, laborers, and the females of mountain hill castes and Kirat ethnic groups are at risk. Most of the drinkers have been taking alcohol for more than 20 years, the most popular drink is 'Local Raksi', a distilled homemade product. The drinkers are more likely to use tobacco; however, they haven't reported any significant health problems. About $9 \%$ of women consumed alcohol even in pregnancy. Therefore, awareness and effective programs with special focus on pregnant women should be launched to discourage the excessive consumption of alcohol, which may lead to many diseases. The females should be encouraged to go for regular health check up in health institutions.

\section{ACKNOWLEDGEMENT}

Research committee of B.P. Koirala Institute of Health Sciences, Dharan, supported the research work. We gratefully acknowledge the input of Tirtha Niraula. We also acknowledge the staff of Dharan municipality for their help in conduction the survey. My thanks are deserves to Mrs. Hom Kumari Sharma and Mrs. Merina Upadhyay. Special thank goes to Prof. Swayam Prakash Sharma for his valuable suggestion on the manuscript.

\section{REFERENCES}

1. Broadening the base of treatment for alcohol problems; report of a study by a committee of the Institute of Medicine. Washington D C, National Academic Press, 1990.

2. Nepal. His Majesty's Government. National Planning Commission Secretariat, Central Bureau of Statistics. Population Census (National Report) 2001. Kathmandu: Central Bureau of Statistics, National Planning Commission Secretariat, His Majesty's Government, 2002: 1.

3. Jingan H P, Shyangwa $P$, Sharma A, Prasad KMR, Khandelwal $\mathrm{S} K$. Prevalence of alcohol dependence in a town in Nepal as assessed by CAGE questionnaire. Addiction2003; 98: 339-43.

4. Sharma A K, Khandelwal S K. Women with alcohol-related problems in Nepal. Addiction 2000; 95 (7) : 1105-8.

5 Fiellin DA, ReidMC, O'Connor P G. Screening for alcohol problem in primary care. Arch Intern Med 2000; 160: 1977-89.
6. Nepal. His Majesty's Government. National Planning Commission Secretariat, Central Bureau of Statistics. Statistical Pocket Book, 1991. Kathmandu: Central Bureau of Statistics, National Planning Commission Secretariat, His Majesty's Government, 1998: 11.

7. B.P. Koirala Institute of Health Sciences. Sunsari Health Interview Survey, 1994. Kathmandu: B.P. Koirala Institute of Health Sciences, 2000: 48-52.

8. Chen K T, Chen C J, Fogot-Campagna A, Narayan K M V. Tobacco, Betel quid, Alcohol, and Illicit Drug Use among 13 to 35 years olds in I-Lan, Rural Taiwan; Prevalence and Risk factors. American Journal of Public Health 2001; 91 (7) : 1130-4.

9. Gronbaek M, Tjonneland A, Johansen D, Stripp C, Overvad K Type of alcohol and drinking pattern in 56, 970 Danish men and women. European Joumal of Clinical Nutrition 2000; 54 (2) ; $174-6$.

10. Balkau B, Randrianjohany A, Papoz L, et al. A prospective study of alcohol use and non-insulin-dependent diabetes mellitus. Am J Epidemiol 1991; 134: 1469-70.

11. Wei M, Gibbons L W, Mitchell $\mathrm{T}$ L, et al. Alcohol intake and incidence of type 2 diabetes in men. Diabetes Care 2000; 23: 18-22.

12. Bloomfield K. Alcohol consumption and alcohol problems among women in European countries. Substance Abuse 2000, 21 (4) : 223-30.

13. Dixit A R, Crum RM. Prospective study of depression and risk a heavy alcohol use in women. American Joumal of Psychiatry $2002 ; 23(2): 751-8$.

14. Sen A. Health: Perception versus observation. BMJ 2002; $324: 860-1$.

15. Shrestha D M, Shrestha B K. Tobacco and Alcohol Use in Nepal. Paper presented at the WHO Regional Consultation on Tobacco and Alcohol, Colombo, Sri Lanka, 17-19 November 1997.

16. Nagata C, Shimizu H, Kametani M et al. Cigarette smoking, alcohol use and colorectal adenoma in Japanese men and women. Disease of the Colon and Rectum 1999; 42 (3) : 33742.

17. Bearer C. Markers to detect drinking during pregnancy. Alcohol Res Health 2001; 25 (3):210-8.

18. Lazzaroni F, Bonassi S, Magnani M et al. Moderate maternal drinking and outcome of pregnancy. Eur J Epidemiol 1993; $9(6)$ : 599-606.

19. Kline J, Shrout P, Stein Z, Susser M, Warburton D. Drinking during pregnancy and spontaneous abortion. Lancet 1980; 2 (8187) : 176-80.

20. Windham G, Von Behren J, Fenster L, Schaefer C, Swan S. Moderate maternal alcohol consumption and risk of spontaneous abortion. Epidemiology 1997; 8 (5) : 509-14.

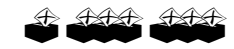

